\title{
BMJ Open An online questionnaire survey of UK general practitioners' knowledge and management of familial hypercholesterolaemia
}

\author{
See Kwok, ${ }^{1,2}$ Jing Pang, ${ }^{3}$ Safwaan Adam, ${ }^{1}$ Gerald F Watts, ${ }^{3,4}$ Handrean Soran ${ }^{1,5}$
}

To cite: Kwok S, Pang J, Adam S, et al. An online questionnaire survey of UK general practitioners' knowledge and management of familial

hypercholesterolaemia. BMJ Open 2016;6:e012691. doi:10.1136/bmjopen-2016012691

- Prepublication history and additional material is available. To view please visit the journal (http://dx.doi.org/ 10.1136/bmjopen-2016012691).

Received 18 May 2016 Revised 9 August 2016 Accepted 22 September 2016

CrossMark

For numbered affiliations see end of article.

Correspondence to

Dr See Kwok;

see.kwok@manchester.ac.uk

\section{ABSTRACT}

Objective: Early diagnosis and treatment of heterozygous familial hypercholesterolaemia $(\mathrm{HeFH})$ is known to be associated with reduced mortality from premature coronary artery disease, but HeFH remains underdiagnosed. This survey aims to determine knowledge and current management of $\mathrm{HeFH}$ in general practice.

Setting: An online questionnaire was administered to general practitioners' (GPs') in the North West of England to assess their knowledge and management of $\mathrm{HeFH}$.

Participants: Practising GPs in the North West of England were contacted by email and invited to complete an online questionnaire. Recruitment discontinued when the target of 100 was reached.

Primary outcome: An assessment of the knowledge and current management of $\mathrm{HeFH}$ in GPs.

Results: $100 \mathrm{GP}$ responses were analysed. Although only $39 \%$ considered themselves to have reasonable knowledge of $\mathrm{HeFH}, 89 \%$ knew that $\mathrm{HeFH}$ was a genetic disorder and $74 \%$ selected the correct lipid profile for diagnosing the condition. More than half $(61 \%)$ were aware of current guidelines on HeFH. Gaps in knowledge were evident when only $30 \%$ correctly identified the prevalence of $\mathrm{HeFH}$ and half were not aware of the pattern of inheritance. Increased cardiovascular risk was underestimated by majority. $33 \%$ thought that they had HeFH patients in their practice confirming underdiagnosis of the condition. Statin therapy was recognised by $94 \%$ to be the right medication for treating HeFH. The majority (82\%) regarded GPs to be the most effective healthcare professional for early recognition of $\mathrm{HeFH}$.

Conclusions: GPs have an above-average knowledge of familial hypercholesterolaemia (FH) and almost universally consider that they have a key role in the early recognition of undiagnosed $\mathrm{HeFH}$ patients in the community. However, there are gaps in awareness that need to be addressed to further enhance the care of $\mathrm{FH}$ in the community.

\section{INTRODUCTION}

Heterozygous familial hypercholesterolaemia $(\mathrm{HeFH})$ is an autosomal dominant condition
Strengths and limitations of this study

- Our survey was confined to the North West of England and may not therefore be wholly representative of GPs in England.

- In the North West of England, only a small percentage of the population lives in rural districts. Majority of the GP practices are therefore urban and suburban.

- The self-selected cohort was likely to be biased as GPs who had more interest in the subject would be expected to respond more readily and these respondents were more likely to have better knowledge of the subject.

- As the survey was conducted anonymously online, there was no information on non-responders.

- We followed a standardised survey model used in 10 countries. This enables responses from different countries to be compared in due course.

characterised by elevated levels of circulating low-density lipoprotein from birth. If untreated, it leads to early-onset coronary artery disease. ${ }^{1}$ The prevalence of $\mathrm{HeFH}$ is about 1 in 500, and early diagnosis and treatment can improve morbidity and mortality from cardiovascular disease. ${ }^{2}$ NICE recommends the use of Simon Broome criteria (see online supplementary appendix box S1) for diagnosing $\mathrm{HeFH}$ and children aged 2-10 years can be screened for familial hypercholesterolaemia $(\mathrm{FH})^{3}$ while European Atherosclerosis Society advocates using the Dutch Lipid Clinic Network criteria (see online supplementary appendix box S2). ${ }^{4}$ Both recommend offering genetic testing to patients who have been clinically diagnosed to confirm diagnosis and to aid screening of family members for the condition.

It is estimated that $<25 \%$ of $\mathrm{HeFH}$ patients are recognised and diagnosed in the UK. ${ }^{4} 5$ General practitioners (GPs) request over $90 \%$ of lipid profile testing ${ }^{6}$ and are 
therefore in a good position to identify undiagnosed $\mathrm{HeFH}$ patients. Early recognition of $\mathrm{HeFH}$ patients and confirmation of diagnosis by genetic testing can lead to accurate referral of patients to secondary care lipid clinics for appropriate cascade screening. ${ }^{7}$ Cascade screening aims to identify first-degree relatives of patients with monogenic mutation who may also have HeFH.

Before strategies are formulated to improve the early recognition and diagnosis of $\mathrm{HeFH}$ in the community, the current level of understanding and awareness of the condition by GPs needs to be assessed.

\section{METHOD}

This survey was part of the ' 10 countries studies' on $\mathrm{HeFH}$ originating from Australia. GPs were requested to complete an online questionnaire to assess their knowledge and understanding of $\mathrm{HeFH}$ and their current clinical practice. The questionnaire was designed to answer key questions concerning the detection, management and care of $\mathrm{FH}$ by expert members of $\mathrm{FH}$ Australasia Network $^{8}$ and by GPs in the Health Networks of the Department of Health of the Government of Western Australia and subsequently piloted in a group of GPs in Western Australia and used in a state and international survey. ${ }^{9} 10$

The questionnaire comprised 19 questions on $\mathrm{HeFH}$ and 5 questions on the participant's demographics (complete questionnaire is listed in the Appendix). The study method has been described before. ${ }^{9}$ The HeFH questions assessed participant's knowledge of $\mathrm{HeFH}$ including clinical features of $\mathrm{HeFH}$, diagnostic lipid profile, prevalence and inheritance of the condition, awareness of genetic confirmation of diagnosis and the association of $\mathrm{HeFH}$ with premature coronary heart disease. They were asked about their awareness of current guidelines and treatment options for $\mathrm{HeFH}$ and their management of patients with the condition, whether they would carry out family screening and whether they would refer to specialist clinics. They were also asked about methods that might help in alerting the possibility of $\mathrm{HeFH}$ and which healthcare professional they considered best placed for early recognition of the disorder.

Demographic data gathered included information on the participant's gender, practice type and clinical experience.

There were no open questions and participants were asked to select the most correct statement. They could choose more than one option in some of the questions.

A minimum of 100 responses were sought from each participating country, and the results of the questionnaire were collected and analysed by Survey Monkey and STATA 12 (StataCorp LP, USA). All participants were anonymised.

GPs in the North West region of England were contacted by email by the Deanery of Health Education
North West and Greater Manchester Comprehensive Local Research Network. A brief outline of the survey was contained in the email which clearly stated that only practising GPs were invited to take part and the link for the online questionnaire was embedded in the email. Recruitment was discontinued when the target was reached.

\section{RESULTS}

A total of 350 GPs were contacted and invited to participate in the survey. Recruitment by email started in June 2015. In total, 111 responses were collected by November 2015 (response rate 31.7\%). Of the respondents, 11 did not fully complete the survey; the remaining 100 responses were analysed.

Of the GP responders, $55 \%$ were women. Majority of responders practised in urban $(41 \%)$ and suburban $(39 \%)$ areas. The mean years in practice of this cohort were $10.3( \pm 9.2)$ years. The demographics of this survey cohort reflect current general practice in the UK, where $65 \%$ of entrants to general practice specialty training are women. ${ }^{11}$

When asked for familiarity with $\mathrm{HeFH}, 39 \%$ rated themselves to be above average (scoring themselves $>4$ ). Sixty-one per cent of them were aware of guidelines on the detection and management of HeFH. Eighty-nine per cent correctly described $\mathrm{HeFH}$ as a genetic disorder, and $74 \%$ chose the correct lipid profile consistent with diagnosis of HeFH. Thirty per cent chose 1 in 500 for $\mathrm{HeFH}$ prevalence, $29 \%$ underestimated the prevalence, while 30\% chose 'Don't know'. Fifty-one per cent thought there was a $50 \%$ chance of first-degree relatives of $\mathrm{HeFH}$ patient also having the condition and $21 \%$ chose 'Don't know'. Fourteen per cent were correct in estimating increased risk of heart disease in $\mathrm{HeFH}$, and $26 \%$ chose 'Don't know'. Fifty-four per cent underestimated the associated risk. On average, responders defined age of onset of premature heart disease to be 49 years in men and 54 years in women. Twenty-eight per cent thought an accurate diagnosis of $\mathrm{HeFH}$ could only be made via genetic test, $52 \%$ disagreed and $20 \%$ chose 'Don't know'. In choosing drugs for treatment of hypercholesterolaemia, respondents could select more than one option. Statins were chosen by the majority of respondents (94\%), and $51 \%$ chose ezetimibe. Statin and ezetimibe combination was chosen by $50 \%$ of respondents for treatment of severe hypercholesterolaemia.

When asked about routine care of patients with documented premature heart disease, respondents could choose more than one option. Taking a detailed family history of coronary artery disease was chosen by $90 \%$. Sixty-five per cent of respondents would also look for tendon xanthomata. Fifty-three per cent looked for arcus cornealis, and $48 \%$ would go on to screen close relatives for $\mathrm{HeFH}$. Table 1 gives a summary of the responses from the survey. Though GPs would not know 
Table 1 Summary of GP's responses to questions about FH awareness, knowledge and practice

\begin{tabular}{|c|c|}
\hline \multicolumn{2}{|l|}{ Awareness } \\
\hline Familiarity of $\mathrm{FH}$ rated as above average & $39 \%$ \\
\hline Awareness about $\mathrm{FH}$ guidelines & $61 \%$ \\
\hline Awareness about lipid specialists & $50 \%$ \\
\hline \multicolumn{2}{|l|}{ Knowledge } \\
\hline Correctly described FH & $89 \%$ \\
\hline Correctly identified lipid profile & $74 \%$ \\
\hline Correctly identified prevalence of $\mathrm{FH}$ in the community & $30 \%$ \\
\hline Correctly identified the transmission rate of $\mathrm{FH}$ to first-degree relatives & $51 \%$ \\
\hline Correctly identified the cardiovascular disease risk in untreated $\mathrm{FH}$ patients & $14 \%$ \\
\hline Correctly identified that genetic testing was not required to accurately diagnose $\mathrm{FH}$ & $52 \%$ \\
\hline Selected statins to best treat hypercholesterolemia & $94 \%$ \\
\hline Selected a combination of statin and ezetimibe to treat severe hypercholesterolemia & $50 \%$ \\
\hline \multicolumn{2}{|l|}{ Practice } \\
\hline Screened patients with premature CAD for family history & $90 \%$ \\
\hline Performed routine family screening of patients with $\mathrm{FH}$ (if GP has $\mathrm{FH}$ patients under their care) & $73 \%$ \\
\hline The most prevalent age for screening young people in a kindred with FH was 13-18 years, which was selected by & $45 \%$ \\
\hline Have referred FH patients to a lipid specialists (if aware of lipid specialist) & $72 \%$ \\
\hline \multicolumn{2}{|l|}{ Opinions on detection } \\
\hline Selected GPs as the most effective healthcare provider for the early detection of FH & $82 \%$ \\
\hline Selected interpretive commenting ${ }^{17}$ on lipid profiles to highlight patients at risk of $\mathrm{FH}$ & $88 \%$ \\
\hline
\end{tabular}

all the $\mathrm{FH}$ patients in their practices, 33\% of respondents believed that they had patients with $\mathrm{HeFH}$ in their practices. In 33 respondents who had HeFH patients in their care, $73 \%$ would routinely screen patient's children and/or close relatives. In a family with premature heart disease, $45 \%$ would test young family members aged $13-$ 18 years despite NICE recommendation of screening children for FH aged $2-10$ years, ${ }^{3} 15 \%$ would test those aged $7-12$ years and $21 \%$ chose 'Don't know'. Fifty per cent of respondents (50 responses) were aware of specialist clinical services for lipid disorders. Of this $50 \%$, $72 \%$ (36 responses) had referred patients to the service. Figure 1 shows patterns of current management of $\mathrm{HeFH}$ in general practice.

To increase the detection of $\mathrm{HeFH}$ in the community, the majority $(92 \%)$ would welcome assistance. Of these, $46 \%$ thought that laboratory alert in a lipid profile report would be useful and $44 \%$ preferred a combination of laboratory report alert, clinical software alert and telephone contact from the laboratory. When asked which healthcare providers were perceived to be most effective at early detection of $\mathrm{HeFH}, 82 \%$ thought that GPs would be the most effective, $48 \%$ chose specialist nurses, $38 \%$ chose lipid specialists and $24 \%$ selected cardiologists.

\section{DISCUSSION}

There was uncertainty among GPs in their own knowledge of $\mathrm{HeFH}$, and only less than half of respondents considered themselves to be familiar with $\mathrm{HeFH}$. Nonetheless, more than half were aware of guidelines and majority showed that they had good knowledge of the diagnostic criteria and treatment of $\mathrm{HeFH}$. The prevalence of HeFH was less well recognised by the participants and only a third of respondents chose the correct option. Half were not aware of the dominant pattern of inheritance of the condition. Only a third thought that they had $\mathrm{HeFH}$ patients in their care; this reflects the continuing low rate of recognition and diagnosis of the condition. ${ }^{5}$

In the Simon Broome criteria, premature heart disease is defined as heart disease before the age of 50 years in second-degree relatives and before the age of 60 years in first-degree relatives. Majority of answers in this survey defined prematurity at a younger age. The association of $\mathrm{HeFH}$ with premature heart disease was recognised, but majority underestimated the risk. Most of respondents realised the importance of taking a detailed family history of coronary artery disease in patients with premature heart disease, and half would look for clinical features of $\mathrm{HeFH}$. When managing patients with diagnosed $\mathrm{HeFH}$, majority would screen the patient's children and/or close relatives for the condition, thus acknowledging it as a genetic disorder. More than half of respondents who were aware of specialist lipid clinics had referred patients to the service. This may reflect the need for GPs to refer patients for confirmation $\mathrm{FH}$ diagnosis.

Undoubtedly, primary care is well placed for early diagnosis of HeFH. ${ }^{12}{ }^{13}$ This was acknowledged by most of the respondents who considered GPs to be the most effective healthcare professional at early detection of $\mathrm{HeFH}$.

Responses to a comparable questionnaire by 191 GPs in Australia were not different to our results. ${ }^{9}$ Twenty-seven per cent knew the correct prevalence, and $29 \%$ recognised the increased cardiovascular risk. An 
A ${ }_{100 \%}$

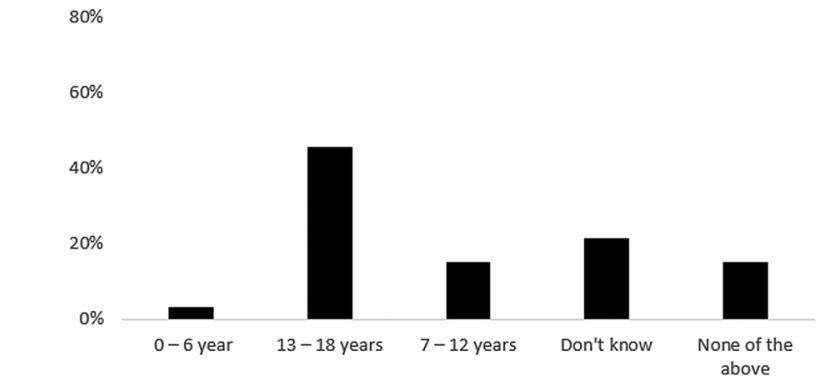

C

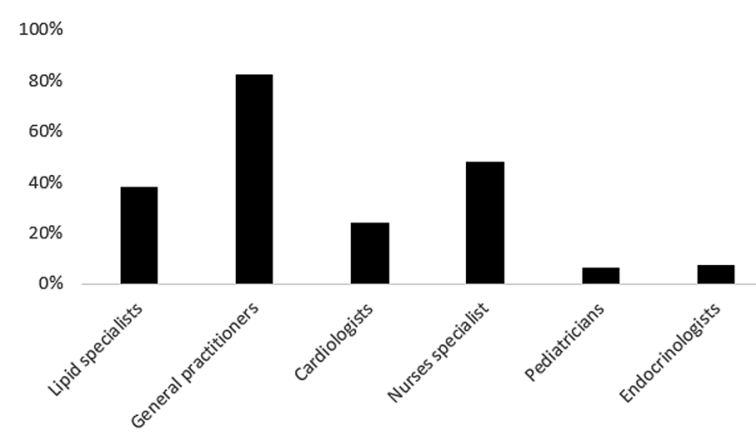

B $100 \%$

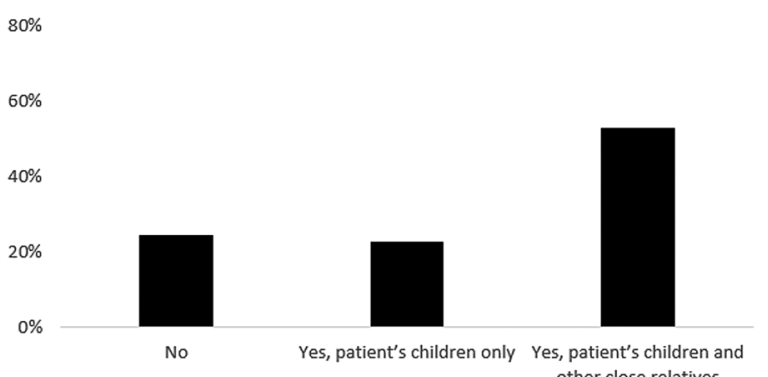

D

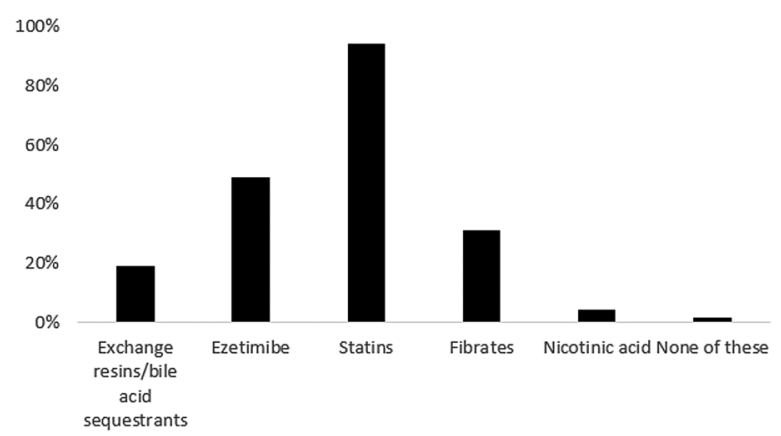

Figure 1 Proportion of GPs who (A) specified these age ranges as the age to test young individuals for $\mathrm{FH}$, (B) would routinely screen close relatives of $\mathrm{FH}$ patients, $(\mathrm{C})$ identified that these healthcare providers have a major role in the early detection of $\mathrm{FH}$ and (D) selected these drugs as useful in the treatment of $\mathrm{FH}$.

internet-based survey of 500 cardiologists in USA showed that there was limited knowledge of $\mathrm{FH}^{14}$ Only $10 \%$ reported good understanding of $\mathrm{FH}, 80 \%$ were unaware of prevalence and $63 \%$ underestimated the associated increased cardiovascular risk. An online questionnaire survey of 230 physicians from 3 economically developed countries in Asia observed that although $70 \%$ considered themselves familiar with $\mathrm{FH}$, only $27 \%$ were aware of prevalence and $70 \%$ underestimated the increased risk. ${ }^{8}$ A recent UK-based questionnaire on $\mathrm{FH}$ knowledge surveyed 443 healthcare professionals. ${ }^{15}$ The results showed that $\mathrm{FH}$ prevalence was underestimated by $23.7 \%$ with $25.5 \%$ unsure and the associated risk underestimated by $77.7 \%$.

If GPs can improve their knowledge of $\mathrm{HeFH}$ and become more confident in making the diagnosis, primary care has immense potential to become an important integrated part of regional screening programme for early recognition and diagnosis of patients with HeFH. These patients can then be referred to Lipid Clinics for cascade screening of their families. ${ }^{16}$

\section{CONCLUSION}

This survey not only showed that GPs recognised they were in an important position to identify undiagnosed HeFH but also demonstrated that they were unfamiliar with the condition. Knowledge of HeFH was patchy, and majority would like assistance with early detection. Appropriate training and educational opportunities would improve the knowledge and awareness of the condition. If these could be partnered by a combination of laboratory input and software alerts, the early diagnosis of $\mathrm{HeFH}$ could be increased effectively.

Author affiliations

${ }^{1}$ Cardiovascular Trials Unit, The Old St Mary's Hospital, Manchester, UK

${ }^{2}$ University of Manchester, Institute of Human Development, Manchester, UK

${ }^{3}$ School of Medicine and Pharmacology, University of Western Australia, Perth, Western Australia, Australia

${ }^{4}$ Lipid Disorders Clinic, Department of Cardiology, Royal Perth Hospital, Perth, Western Australia, Australia

${ }^{5}$ Central Manchester University Hospitals NHS Foundation Trust, Manchester, UK

Acknowledgements Support from Manchester Wellcome Trust Clinical Research Facility and Greater Manchester Comprehensive Local Research Network is acknowledged.

Contributors GFW and JP devised the study and questionnaire. SK, SA and HS recruited participants in the UK. SK and JP collated the survey results. SK drafted the manuscript to which all the other authors contributed.

Funding This study was funded by International Atherosclerosis Society (IAS) and Pfizer Independent Grants for Learning \& Change (Grant No. 10839501).

Competing interests None declared.

Provenance and peer review Not commissioned; externally peer reviewed.

Data sharing statement No additional data are available.

Open Access This is an Open Access article distributed in accordance with the Creative Commons Attribution Non Commercial (CC BY-NC 4.0) license, which permits others to distribute, remix, adapt, build upon this work noncommercially, and license their derivative works on different terms, provided the original work is properly cited and the use is non-commercial. See: http:// creativecommons.org/licenses/by-nc/4.0/ 


\section{REFERENCES}

1. Stone NJ, Levy RI, Fredrickson DS, et al. Coronary artery disease in 116 kindred with familial type II hyperlipoproteinemia. Circulation 1974;49:476-88.

2. Neil A, Cooper J, Betteridge J, et al. Reductions in all-cause, cancer, and coronary mortality in statin-treated patients with heterozygous familial hypercholesterolaemia: a prospective registry study. Eur Heart J 2008;29:2625-33.

3. Minhas R, Humphries SE, Davies D, et al. (Guideline Development Group). http://www.nice.org.uk/guidance/cg71

4. Nordestgaard BG, Chapman MJ, Humphries SE, et al., European Atheroslcerosis Society Consensus Panel. Familial hypercholesterolaemia is underdiagnosed and undertreated in the general population: guidance for clinicians to prevent coronary heart disease: consensus statement of the European Atherosclerosis Society. Eur Heart J 2013;34:3478-90.

5. Neil HAW, Hammond T, Huxley R, et al. Extent of underdiagnosis of familial hypercholesterolaemia in routine practice: prospective registry study. BMJ 2000;321:148.

6. Bell DA, Hooper AJ, Bender R, et al. Opportunistic screening for familial hypercholesterolaemia via a community laboratory. Ann Clin Biochem 2012;49:534-7.

7. Hadfield SG, Humphries SE. Implementation of cascade testing for the detection of familial hypercholesterolaemia. Curr Opin Lipid 2005;16:428-33.

8. Bell DA, Garton-Smith J, Vickery A, et al. Familial hypercholesterolaemia in primary care: knowledge and practices among general practitioners in Western Australia. Heart Lung Cir 2014;23:309-13.

9. Pang J, Sullivan DR, Harada-Shiba M, et al. Significant gaps in awareness of familial hypercholesterolemia among physicians in selected Asia-Pacific countries: a pilot study. J Clin Lipidol 2015;9:42-8.

10. Pang J, Lansberg PJ, Watts GF. International developments in the care of familial hypercholemia: where now and where to next? J Atheroscler Thromb 2016;23:505-19.

11. In-depth review of the general practitioner workforce. 2014. http:// www.cfwi.org.uk

12. Gill PJ, Harnden A, Karpe F. Familial hypercholesterolaemia. BMJ 2012;344:e3228.

13. Gray J, Jaiyeola A, Whiting $M$, et al. Identifying patients with familial hypercholesterolaemia in primary care: an informatics-based approach in one primary care centre. Heart 2008;94:754-8.

14. Foody JM. Familial hypercholesterolemia: an under-recognized but significant concern in cardiology practice. Clin Cardiol 2014;37:119-25

15. Schofield J, Kwok S, France M, et al. Knowledge gaps in the management of familial hypercholesterolaemia. A UK based survey. Atherosclerosis 2016;252:161-5.

16. Ned RM, Sijbrands EJG. Cascade screening for familial hypercholesterolemia (FH). PLoS Curr 2011;3:RRN1238.

17. Bell DA, Bender R, Hooper AJ, et al. Impact of interpretative commenting on lipid profiles in people at high risk of familial hypercholesterolaemia. Clin Chim Acta 2013;422:21-5. 